\title{
Beta-blockers and glioma: a systematic review of preclinical studies and clinical results
}

\author{
Ishaan Ashwini Tewarie ${ }^{1,2,3}$ • Joeky T. Senders ${ }^{1,3,4} \cdot$ Alexander F. C. Hulsbergen ${ }^{1,3,4} \cdot$ Stijn Kremer ${ }^{1}$. \\ Marike L. D. Broekman ${ }^{1,3,4}$
}

Received: 26 November 2019 / Revised: 20 February 2020 / Accepted: 28 February 2020 / Published online: 14 March 2020

(C) The Author(s) 2020

\begin{abstract}
Given the median survival of 15 months after diagnosis, novel treatment strategies are needed for glioblastoma. Beta-blockers have been demonstrated to inhibit angiogenesis and tumor cell proliferation in various cancer types. The aim of this study was to systematically review the evidence on the effect of beta-blockers on glioma growth. A systematic literature search was performed in the PubMed, Embase, Google Scholar, Web of Science, and Cochrane Central to identify all relevant studies. Preclinical studies concerning the pharmacodynamic effects of beta-blockers on glioma growth and proliferation were included, as well as clinical studies that studied the effect of beta-blockers on patient outcomes according to PRISMA guidelines. Among the 980 citations, 10 preclinical studies and 1 clinical study were included after title/abstract and full-text screening. The following potential mechanisms were identified: reduction of glioma cell proliferation $(n=9)$, decrease of glioma cell migration $(n=2)$, increase of drug sensitivity $(n=1)$, induction of glioma cell death $(n=1)$. Beta-blockers affect glioma proliferation by inducing a brief reduction of cAMP and a temporary cell cycle arrest in vitro. Contrasting results were observed concerning glioma cell migration. The identified clinical study did not find an association between beta-blockers and survival in glioma patients. Although preclinical studies provide scarce evidence for the use of beta-blockers in glioma, they identified potential pathways for targeting glioma. Future studies are needed to clarify the effect of beta-blockers on clinical endpoints including survival outcomes in glioma patients to scrutinize the value of beta-blockers in glioma care.
\end{abstract}

Keywords Beta-blockers $\cdot$ Neurosurgery $\cdot$ Glioma $\cdot$ Overall survival

Electronic supplementary material The online version of this article (https://doi.org/10.1007/s10143-020-01277-4) contains supplementary material, which is available to authorized users.

Marike L. D. Broekman

marikebroekman@gmail.com

1 Department of Neurosurgery, Haaglanden Medical Center, The Hague, The Netherlands

2 Faculty of Medicine, Erasmus University Rotterdam/Erasmus Medical Center, Rotterdam, The Netherlands

3 Computational Neurosciences Outcomes Center, Department of Neurosurgery, Brigham and Women's Hospital, Harvard Medical School, Boston, MA, USA

4 Department of Neurosurgery, Leiden University Medical Center, Leiden, The Netherlands

\section{Introduction}

Glioblastomas are the most common primary malignant brain tumors [1]. With a median survival of just 16 months despite neurosurgical resection and chemoradiation, prognosis is poor and novel treatment strategies are needed [2-6].

Beta-blockers are competitive antagonists of the sympathetic effects of catecholamines on beta-adrenergic receptors $[7,8]$. They have affinity for beta-1-, beta-2-, or beta-3adrenergic receptors but do not evoke a response from these receptors. Therefore, the binding of a beta-blocker and adrenergic receptor prevents the binding and subsequent effects of catecholamines [9]. In cardiovascular diseases, beta-blockers are widely prescribed to counter these effects, including an increase in heart rate and blood pressure. Within the field of oncology, catecholamines have been demonstrated to stimulate secretion of pro-angiogenic factors such as vascular endothelial growth factor (VEGF) and boost tumor migration in several cancer cell lines [10-12]. Consequently, beta-blockers 
have been reported to inhibit angiogenesis and tumor cell proliferation in breast cancer, multiple myeloma, pancreatic cancer, and neuroblastoma cell lines by decreasing catecholamine-driven proliferation [13-16]. While the presence of beta-1-, beta-2-, and beta-3-adrenergic receptors has been demonstrated in glioma cell lines [17-19], the potential efficacy of beta-blockers in this cancer type remains to be elucidated [20]. The aim of this study was to systematically review preclinical and clinical studies on the effects of betablockers on glioma.

\section{Methods}

\section{Search strategy}

A systematic literature review according to the Preferred Reporting Items for Systematic Reviews and Meta-Analyses (PRISMA) guidelines [21]. The Embase, Medline Ovid (PubMed), Web of Science, Cochrane Central, and Google Scholar databases were searched to identify all relevant articles up to May 10, 2019. A professional librarian was consulted in order to construct a search syntax, which used synonyms for glioma and beta-blockers (suppl. Table 1). All selective and non-selective beta-blockers were included in the syntax. Clinical studies were included if they investigated the association between beta-blocker use and survival or other outcomes in glioma patients. Furthermore, all preclinical studies that investigated the effect of beta-blockers in glioma cell lines or in animal models were included as well. Case reports or articles written in languages other than Dutch or English were excluded. No restrictions based on the date of publication were used. This systematic search was complemented by screening the references of the included articles to identify additional publications. Titles and abstracts of retrieved articles were first screened by two independent authors (IRT, SK). Afterwards, two authors read the full text of potentially suitable articles separately (IRT, SK). Discrepancies were resolved by discussion and, if necessary, a third reviewer was consulted (JS).

\section{Data extraction}

The following data were extracted from the included preclinical studies: year of publication, name of the first author, type of cell line, beta-blocker used, optimum concentration, cyclic adenosine monophosphate (cAMP) formation, morphology, and percentage of beta-adrenergic receptor blocked as determined relative to all cells on the plate. From clinical studies, the following parameters were extracted: year of publication, name of the first author, glioma categorized by grade, betablocker used, number of patients, 1-year survival rate, and median overall survival in months.

\section{Results}

The search identified 980 unique studies. After screening of title and abstract followed by screening of the full text, we included 11 studies (10 preclinical and one clinical) that examined the effect of beta-blockers on glioma growth and patient outcomes (Fig. 1) [18, 20, 22-30]. Characteristics of all included preclinical studies can be found in Table 1.

The identified preclinical studies investigated the following mechanisms through which beta-blockers could affect glioma growth: (i) reduction of glioma cell proliferation [18, 20, 23-26, 28, 29], (ii) decrease of tumorigenesis and glioma cell migration [22, 27], (iii) increase of drug sensitivity [24], and (iv) induction of cell death [24].

\section{Reduction of glioma cell proliferation}

Eight studies investigated the effect of beta-blockers on glioma cell proliferation $[18,20,23-26,28,29]$. Two pathways were identified through which beta-blockers could potentially reduce glioma cell proliferation: a decrease in intracellular cyclic adenosine monophosphate (cAMP) levels resulting in lower cell activity $[18,20,23-26,28,29]$ and a timedependent cell cycle arrest [18].

\section{cAMP and cell metabolism}

In two in vitro studies, elevated cAMP levels were associated with increased glioma cell proliferation and stellate transformation [18, 24]. Stellate transformation indicates that the (tumor) cell is more active, i.e., cytoplasmatic processes rise. Therefore, overall cell activity and proliferation are stimulated in this formation. This is a negative development in the treatment of a tumor. The spherical morphology could be induced by beta-agonists and suppressed by beta-blockers [18]. This process indicates increased tumor cell activity and extensive proliferation and could be induced by beta-agonists and suppressed by beta-blockers [18]. A schematic representation of the cAMP pathway in glioma can be found in Fig. 2. Six studies further investigated the relationship between beta-blockers and reduced cAMP levels, as well as the underlying pathways [23-26, 28, 29]. First, beta-blockers initiated a time- and dosedependent decrease in cAMP formation caused by a blockade of the substrate (i.e., beta-agonists) bound activity [18, 24-26, 28, 29]. Second, suppression of the unbound, constitutive activity of adrenergic receptors was observed (i.e., beta-blockers functioning as inverse agonists) [28]. In three studies, however, maximum levels of cAMP formation could still be reached despite a blockade of $>90 \%$ of the beta-adrenergic receptors. This indicates that cAMP formation possibly occurs at receptor sites other than the 


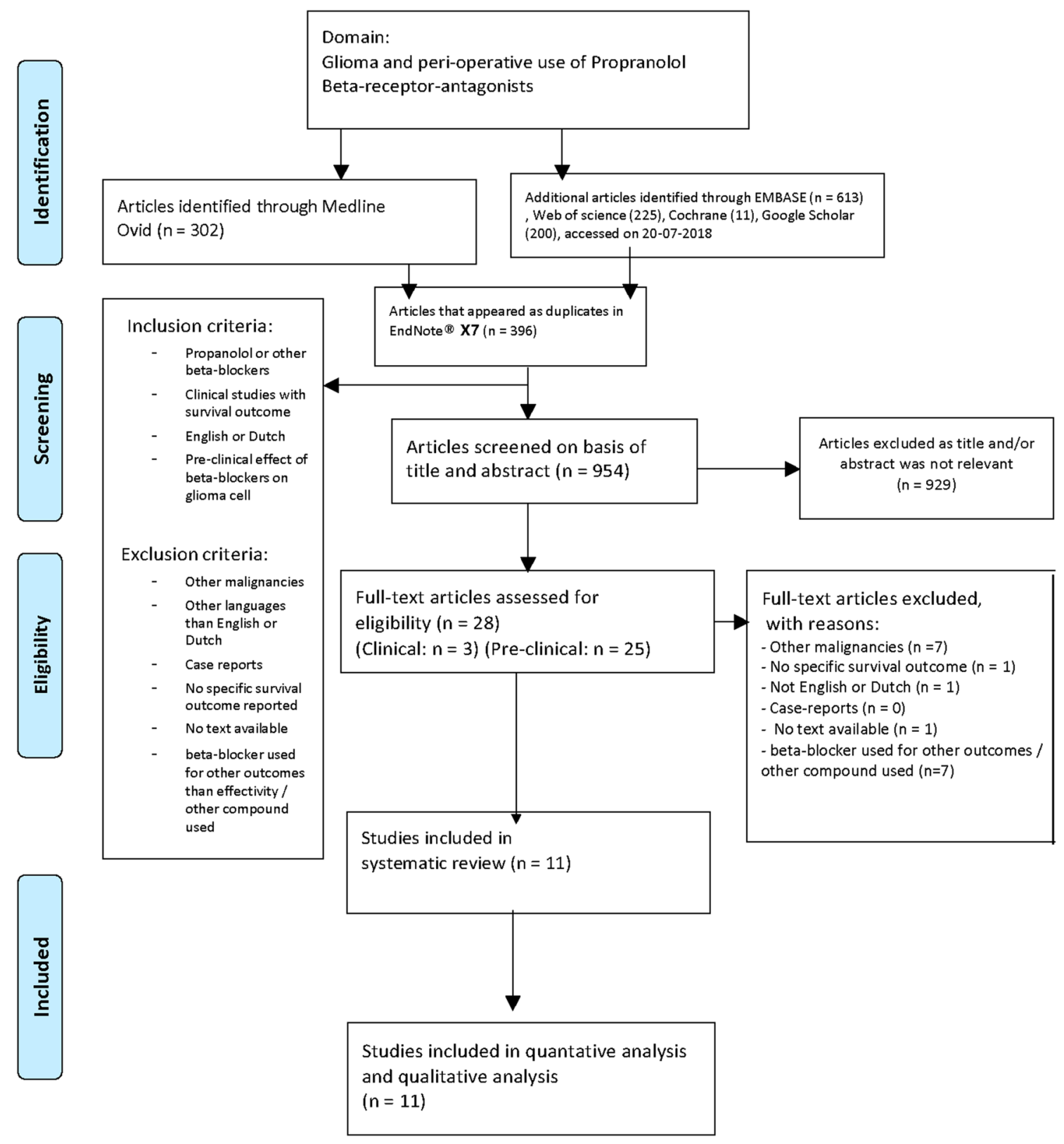

Fig. 1 Flowchart

beta-adrenergic variant [23, 28, 29]. Lastly, beta-blockers initiated a time- and dose-dependent decrease in adenylate cyclase, a protein that catalyzes the conversion of adenosine 5-triphosphate (ATP) to cAMP [18, 23-26, 28, 29].

\section{Time-dependent cell cycle arrest}

Erguven et al. explored the effect of beta-blockers on the cell cycle [24]. In their study, carvedilol appeared to increase the percentage of glioma cells in the mitotic S- and G2-phases at $24 \mathrm{~h}$ after administration. However, it induced a cell cycle arrest in the G0/G1 phase at $72 \mathrm{~h}$ after administration.

\section{Decrease of glioma cell migration}

Two studies examined the effect of beta-blockers on angiogenesis and glioma cell migration [22, 27]. Pavlova et al. injected rats with rat $\mathrm{C} 6$ glioma cells and treated half of them with ICI118551 p.o., a specific beta-2-receptor antagonist, starting from the first day after implantation [27]. Upon implantation of the C6 glioma cells into the caudate putamen area, the control group was divided in rats that received either saline or isoproterenol in the same volume. The rats that received ICI-118551 survived longer than the control group (median 45 versus 20 days). All rats that received isoproterenol developed metastasis in the first 7 days after implantation. Furthermore, confocal 
Table 1 Characteristics of preclinical articles

\begin{tabular}{|c|c|c|c|c|c|c|c|}
\hline Author & Year & $\beta$-Blocker & Cell line & $\beta$-Agonist & Anti-tumor effect & Main observation & $\Delta$ control group* \\
\hline Edström et al. & 1975 & Sotalol & Human glioma cells & Isoproterenol & Antiproliferative & cAMP decrease & $92 \%$ \\
\hline Terasaki et al. & 1979 & Propranolol & Rat C6 glioma cells & Isoproterenol & Antiproliferative & cAMP decrease & $\mathrm{x}$ \\
\hline Homburger et al. & 1984 & Pindolol & Rat C6 glioma cells & Isoproterenol & $\mathrm{x}$ & $<100 \% \beta$-receptors blocked & $52.2 \%$ \\
\hline Homburger et al. & 1985 & Pindolol & Rat C6 glioma cells & Isoproterenol & $\mathrm{x}$ & $<100 \% \beta$-receptors blocked & $85 \%$ \\
\hline Balmforth et al. & 1986 & Propranolol & G-CCM ${ }^{\mathrm{a}}$ & Isoprenaline & $\begin{array}{l}\text { Inhibition } \\
\text { secondary sites }\end{array}$ & $\mathrm{x}$ & $\mathrm{x}$ \\
\hline Conroy et al. & 1988 & Propranolol & AC glioma cells & Isoproterenol & Antiproliferative & Decrease in stellate morphology & $45 \%$ \\
\hline Sokolowska et al. & 2005 & Propranolol & Rat C6 glioma cells & Isoprenaline & Inverse agonism & cAMP decrease & $80 \%$ \\
\hline Annabi et al. & 2009 & Propranolol & $\mathrm{HBMEC}^{\mathrm{b}}$ & $\mathrm{x}$ & Anti-angiogenic & MMP-9 decrease & $40 \%$ \\
\hline Erguven et al. & 2009 & Carvedilol & Rat C6 glioma cells & $\mathrm{x}$ & Antiproliferative & cAMP decrease & $80 \%$ \\
\hline Pavlova et al. & 2018 & Propranolol & In vivo & $\mathrm{x}$ & Antimigration & $\begin{array}{l}\text { Decrease in } \\
\text { migration/increase } \\
\text { in survival }\end{array}$ & $20 \% / 50 \%$ \\
\hline
\end{tabular}

The " $\mathrm{x}$ " implies that they have not reported or did not use this variable in the study

${ }^{\text {a }} G$-CCM human astrocytoma cell line

${ }^{\mathrm{b}}$ HBMEC human microvascular endothelial cells of the brain

*All shown percentages demonstrate the relative difference in the main observation between control group (beta-agonist + cell line) and beta-blocker + beta-agonist + cell line

imaging of fluorescent gliomas in vivo and ex vivo revealed that blockade of the beta-2-adrenergic receptors decreased glioma cell migration by $20 \%$ and reduced the disruption of the blood-brain barrier significantly $(p<0.001)$.
Annabi et al. did not observe a direct association with cell migration in vitro but reported an association between propranolol administration and matrix metalloproteinase nine (MMP-9) and Hu antigen R (HuR) [22]. MMP-2 was not

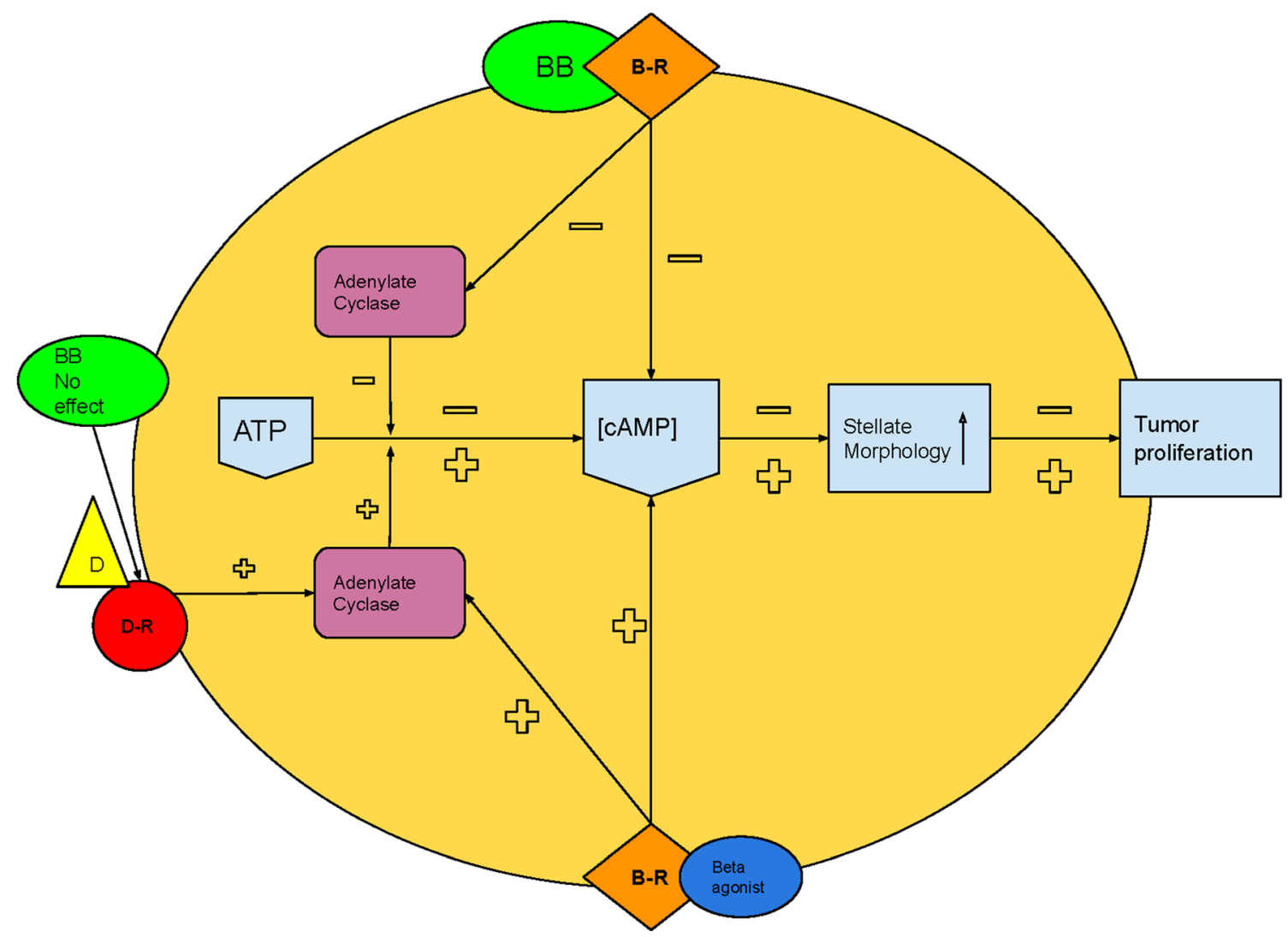

Fig. 2 Schematic illustration of cAMP pathway 
affected by propranolol. MMP-9 and MMP-2 are associated with the integrity of the blood-brain barrier [31,32] and have been shown to increase the invasiveness of human glioma cells [33, 34]. Annabi et al. observed that MMP-9 levels were positively correlated with the expression of beta-adrenergic receptors and reduced after treatment with propranolol [22]. Moreover, capillary structure formations were inhibited by propranolol in vitro. HuR and RNA-binding proteins are known to positively affect proliferation, survival, and translational efficiency in other cancer types including lung, breast, ovarian, and colon cancer cells [35-41]. Annabi et al. observed that propranolol does not directly affect HuR expression, but that it inhibits HuR translocation into cytosol where it stabilizes MMP-9 [22].

\section{Increase of drug sensitivity}

One study investigated the effect of beta-blockers on the sensitivity of glioma cells to cytotoxic drugs [24]. In this in vitro study, Erguven et al. targeted the p-glycoprotein (p-Gp), a key efflux transporter in the blood-brain barrier known to attenuate the efficacy of various drugs by limiting transport to the central nervous system [42, 43]. Carvedilol administration in combination with imatinib, a kinase inhibitor that is primarily used for leukemia, resulted in increased imatinib-induced cell death [24].

\section{Induction of glioma cell death}

Erguven et al. also examined the effect of beta-blockers on programmed cell death [24]. They showed that carvedilol treatment established lytic changes in glioma cells, especially in the mitochondria, thereby initiating cell apoptosis. A single dose of carvedilol induced apoptotic cell death of 5\% in all monolayer-cultured C6 glioma cells after $24 \mathrm{~h}(p<0.05)$. At $72 \mathrm{~h}$, this percentage of apoptotic cells was decreased to $2 \%$ $(p<0.01)$ [24]. The underlying mechanism, however, remains to be elucidated [24] (Fig. 3).

\section{Clinical evidence of beta-blockers affecting glioma}

Johansen et al. studied the effect of beta-blockers on recurrent glioblastoma in a retrospective cohort of 218 patients [30]. This study compared patients that received beta-blockers with patients that did not receive any antihypertensive drug, while both groups were being treated with bevacizumab. After adjusting for multifocal disease, use of steroids, WHO performance status, and neurocognitive deficits, no association was found between beta-blocker usage and overall survival (hazard ratio 0.79 ; CI $95 \% 0.38-1.65$; $p$ value 0.53 ) or progression-free survival (hazard ratio 0.78 ; CI $95 \% 0.36-$ $1.68 ; p$ value 0.52 ).

\section{Discussion}

This systematic review synthesizes all preclinical and clinical evidence on the effect of beta-blockers on glioma growth and patient outcomes. Preclinical studies have identified several potential mechanisms of action through which beta-blockers might have a potential effect on (i) glioma cell proliferation [18, 20, 23-26, 28, 29], (ii) glioma cell migration [22, 27], (iii) drug sensitivity [24], and (iv) glioma cell death [24]. First, betablockers were demonstrated to lower tumor cell proliferation by decreasing levels of cAMP with dose and time dependency. Second, after administering beta-blockers a time-dependent cell cycle arrest was observed [18, 20, 23-26, 28, 29]. Third, blockade of the beta-2-adrenergic receptor decreased glioma cell migration [27]. Last, p-glycoprotein expression is possibly altered by beta-blockers resulting in an increase in drug sensitivity. One observational clinical study was included, which did not find an effect of beta-blockers on overall survival or progression-free survival in recurrent glioblastoma [30].

Beta-blockers have been suggested to reduce the risk of prostate cancer [44], as well as hepatocellular carcinomas in hepatitis $C$ patients [45], and to prolong survival and reduce mortality in breast cancer patients [46]. In addition, it has been demonstrated that beta-blockers affect cell proliferation and migration in neuroblastoma cell lines [13]. Moreover, betablockers were demonstrated to elevate the therapeutic concentration of co-administered medications. Interestingly, this elevation of drug sensitivity did not seem to be related to a variation in p-Gp expression [13].

The current literature provides limited evidence to integrate beta-blockers into glioma treatment. However, the preclinical studies have identified various mechanisms through which the application of non-selective beta-blockers could potentially attenuate glioma cell proliferation.

Microglia have been demonstrated to upregulate matrixaltering enzymes, especially MMP-2 and MMP-9, to facilitate glioma infiltration. Downregulation of the MMP-cascade results in less glioma invasion, angiogenesis, and growth [47]. This systematic review identified contrasting results concerning the effect of propranolol on cell migration and the potential role of MMP-2 and MMP-9 [22, 27]: MMP-2 levels were not affected by propranolol, while MMP-9 levels were. Still, propranolol was not observed to directly affect glioma cell migration. This could indicate that even though both MMP-2 and MMP-9 affect migration, blocking one of these does not preclude alternative pathways from promoting cell migration. Although MMP-9 and MMP-2 are mostly similar substrates, it is hypothesized that they are regulated by different mediators, expressed under different conditions, and therefore have different instances in which they affect the tumor micro-environment $[48,49]$. However, more studies are needed to elucidate how MMP-9 and/or MMP-2 directly or indirectly affect glioma cell migration in patients. 
Fig. 3 Morphological observations and effect on glioma cell proliferation

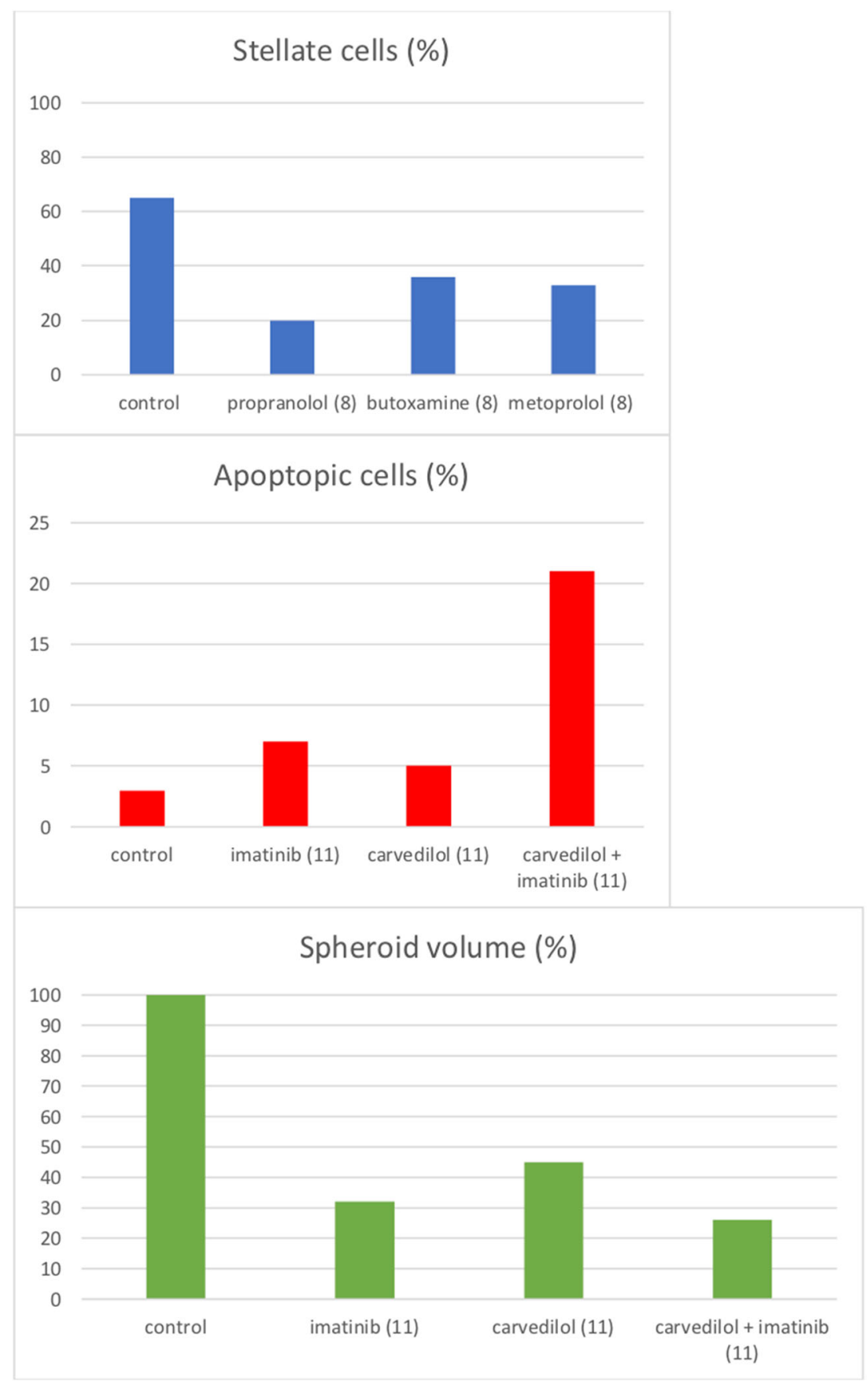

Finally, the observational study did not find a significant effect of beta-blockers on the survival rate of recurrent glioblastoma patients. In the multivariate analysis, neurocognitive deficits and steroids were included without reported association with overall survival. The aforementioned variables were included as a result of a study which reviewed variables influencing the quality of life and prognosis in glioblastoma patients [50]. The statistical insignificance of the hazard ratio of 0.79 could be due to an underpowered analysis. Moreover, the research question of this study was focused on angiotensin system inhibitors and the sample size of the sub-analysis regarding beta-blockers was not reported [30]. Pavlova et al. [27] observed a survival increase in rats with glioma. The significant decrease of glioma cell migration combined with the observation that all rats receiving isoproterenol developed metastasis within the first 7 days after implantation emphasizes the possibility of the beta-adrenergic pathway being a tumor migration pathway [27]. However, additional studies are still needed to elucidate this question.

There are limitations to the present review. Most studies predominantly focused on associations between betablockers and mediator enzymes (such as MMP-9) instead of 
examining their direct effect on clinical (e.g., survival and tumor progression) or physiological endpoints (e.g., cell proliferation and cell migration). As such, no inferences can be drawn on the direct association between beta-blockers and these endpoints. Studies that consider mediating proteins as surrogate endpoints rely on the strong assumption that these mediators are included in the causal pathway. Outcomes such as cell growth or migration are independent of such assumptions and thus would be able to support more robust conclusions. Additionally, this systematic review is subject to publication bias. Despite these limitations, we believe this review provides valuable insights into the potential utility of betablockers in glioma care and valuable target mechanisms for the development of anti-glioma drugs. To the best of our knowledge, this is the first systematic review synthesizing the current body of evidence on the effects of beta-blockers on glioma growth and patient outcomes, both in the preclinical and clinical realms.

\section{Future research}

Preclinically, almost all studies were performed in vitro. Therefore, future research on the effect of beta-blockers in addition to conventional treatment of glioma should ideally be performed in vivo. Preclinical studies could further investigate the effect of beta-blockers in vivo by measuring clinically relevant outcomes (e.g., survival and recurrence rates) and physiological endpoints (e.g., both cell proliferation and cell migration) in mice. Preliminary results of an ongoing clinical study suggest that propranolol in combination with etodolac (VT-122) might have a positive effect on survival in recurrent glioblastoma patients. Hypothetically, VT-122 attenuates inflammation and thereby increases tolerability for anticancer therapy [51,52]. Additionally, including medication and beta-blocker usage in large prospective neurooncological registries could be valuable in investigating the effect on cancer-related patient outcomes.

\section{Conclusion}

Although preclinical research provides limited evidence for the effectiveness of beta-blocker usage in glioma care, this review identifies potential mechanisms through which betablockers might affect glioma proliferation, migration, drug sensitivity, and programmed cell death. However, the effect on patient outcomes remains unclear due to the limited body of clinical evidence. In addition to identifying potential mediators, future preclinical research should further explore the effect of beta-blockers on physiological and clinical endpoints. Including medication and beta-blocker usage in large prospective neuro-oncological registries could be a valuable step for examining the direct or conjunct effect on cancerrelated patient outcomes.

Acknowledgments We would like to express our great appreciation to Wichor M. Bramer, librarian of Erasmus Medical Center, who was helpful in building this search query.

\section{Compliance with ethical standards}

Conflict of interests The authors declare that they have no competing interests.

Ethical approval This article does not contain any studies with human participants or animals performed by any of the authors.

Open Access This article is licensed under a Creative Commons Attribution 4.0 International License, which permits use, sharing, adaptation, distribution and reproduction in any medium or format, as long as you give appropriate credit to the original author(s) and the source, provide a link to the Creative Commons licence, and indicate if changes were made. The images or other third party material in this article are included in the article's Creative Commons licence, unless indicated otherwise in a credit line to the material. If material is not included in the article's Creative Commons licence and your intended use is not permitted by statutory regulation or exceeds the permitted use, you will need to obtain permission directly from the copyright holder. To view a copy of this licence, visit http://creativecommons.org/licenses/by/4.0/.

\section{References}

1. Ostrom QT, Gittleman H, Truitt G, Boscia A, Kruchko C, Barnholtz-Sloan JS (2018) CBTRUS statistical report: primary brain and other central nervous system tumors diagnosed in the United States in 2011-2015. Neuro-Oncology 20:iv1-iv86. https://doi.org/10.1093/neuonc/noy131

2. Stupp R, Mason WP, van den Bent MJ, Weller M, Fisher B, Taphoorn MJ, Belanger K, Brandes AA, Marosi C, Bogdahn U, Curschmann J, Janzer RC, Ludwin SK, Gorlia T, Allgeier A, Lacombe D, Cairncross JG, Eisenhauer E, Mirimanoff RO (2005) Radiotherapy plus concomitant and adjuvant temozolomide for glioblastoma. N Engl J Med 352:987-996. https://doi.org/10. 1056/NEJMoa043330

3. Bi WL, Beroukhim R (2014) Beating the odds: extreme long-term survival with glioblastoma. Neuro-Oncology 16:1159-1160. https://doi.org/10.1093/neuonc/nou166

4. Chinot OL, Wick W, Mason W, Henriksson R, Saran F, Nishikawa R, Carpentier AF, Hoang-Xuan K, Kavan P, Cernea D, Brandes AA, Hilton M, Abrey L, Cloughesy T (2014) Bevacizumab plus radiotherapy-temozolomide for newly diagnosed glioblastoma. $\mathrm{N}$ Engl J Med 370:709-722. https://doi.org/10.1056/ NEJMoa1308345

5. Johnson DR, Leeper HE, Uhm JH (2013) Glioblastoma survival in the United States improved after Food and Drug Administration approval of bevacizumab: a population-based analysis. Cancer 119:3489-3495. https://doi.org/10.1002/cncr.28259

6. Rick J, Chandra A, Aghi MK (2018) Tumor treating fields: a new approach to glioblastoma therapy. J Neuro-Oncol 137:447-453. https://doi.org/10.1007/s11060-018-2768-x

7. Frishman WH, Saunders E (2011) Beta-adrenergic blockers. J Clin Hypertens (Greenwich) 13:649-653. https://doi.org/10.1111/j. 1751-7176.2011.00515.x 
8. Al-Majed AA, Bakheit AHH, Abdel Aziz HA, Alajmi FM, AlRabiah H (2017) Propranolol. Profiles Drug Subst Excip Relat Methodol 42:287-338. https://doi.org/10.1016/bs.podrm.2017.02. 006

9. Oliver E, Mayor F Jr, D’Ocon P (2019) Beta-blockers: historical perspective and mechanisms of action. Rev Esp Cardiol (Engl Ed) 72:853-862. https://doi.org/10.1016/j.rec.2019.04.006

10. Chakroborty D, Sarkar C, Basu B, Dasgupta PS, Basu S (2009) Catecholamines regulate tumor angiogenesis. Cancer Res 69: 3727-3730. https://doi.org/10.1158/0008-5472.Can-08-4289

11. Lamy S, Lachambre MP, Lord-Dufour S, Beliveau R (2010) Propranolol suppresses angiogenesis in vitro: inhibition of proliferation, migration, and differentiation of endothelial cells. Vasc Pharmacol 53:200-208. https://doi.org/10.1016/j.vph.2010.08.002

12. Yang EV, Kim SJ, Donovan EL, Chen M, Gross AC, Webster Marketon JI, Barsky SH, Glaser R (2009) Norepinephrine upregulates VEGF, IL-8, and IL-6 expression in human melanoma tumor cell lines: implications for stress-related enhancement of tumor progression. Brain Behav Immun 23:267-275. https://doi.org/ 10.1016/j.bbi.2008.10.005

13. Pasquier E, Street J, Pouchy C, Carre M, Gifford AJ, Murray J, Norris MD, Trahair T, Andre N, Kavallaris M (2013) Betablockers increase response to chemotherapy via direct antitumour and anti-angiogenic mechanisms in neuroblastoma. Br J Cancer 108:2485-2494. https://doi.org/10.1038/bjc.2013.205

14. Zhang D, Ma Q, Shen S, Hu H (2009) Inhibition of pancreatic cancer cell proliferation by propranolol occurs through apoptosis induction: the study of beta-adrenoceptor antagonist's anticancer effect in pancreatic cancer cell. Pancreas 38:94-100. https://doi. org/10.1097/MPA.0b013e318184f50c

15. Kozanoglu I, Yandim MK, Cincin ZB, Ozdogu H, Cakmakoglu B, Baran Y (2013) New indication for therapeutic potential of an old well-known drug (propranolol) for multiple myeloma. J Cancer Res Clin Oncol 139:327-335. https://doi.org/10.1007/s00432-0121331-y

16. Pasquier E, Ciccolini J, Carre M, Giacometti S, Fanciullino R, Pouchy C, Montero MP, Serdjebi C, Kavallaris M, Andre N (2011) Propranolol potentiates the anti-angiogenic effects and anti-tumor efficacy of chemotherapy agents: implication in breast cancer treatment. Oncotarget 2:797-809. https://doi.org/10.18632/ oncotarget. 343

17. He J-J, Zhang W-H, Liu S-L, Chen Y-F, Liao C-X, Shen Q-Q, Hu P (2017) Activation of $\beta$-adrenergic receptor promotes cellular proliferation in human glioblastoma. Oncol Lett 14:3846-3852. https:// doi.org/10.3892/ol.2017.6653

18. Conroy WG, Peoples RW, Isom GE (1989) Identification of functional beta-adrenergic receptors on AC glioma cells. Biochem Pharmacol 38:3175-3178. https://doi.org/10.1016/0006-2952(89) 90610-2

19. Jozwiak-Bebenista M, Wiktorowska-Owczarek A, Kowalczyk E (2016) Beta-adrenoceptor-mediated cyclic AMP signal in different types of cultured nerve cells in normoxic and hypoxic conditions. Mol Biol (Mosk) 50:838-846. https://doi.org/10.7868/ s0026898416050074

20. Edstrom A, Kanje M, Lofgren P, Walum E (1975) Drug induced alterations in morphology and level of cAMP in cultured human glioma cells. Exp Cell Res 95:359-364. https://doi.org/10.1016/ 0014-4827(75)90561-3

21. Liberati A, Altman DG, Tetzlaff J, Mulrow C, Gotzsche PC, Ioannidis JP, Clarke M, Devereaux PJ, Kleijnen J, Moher D (2009) The PRISMA statement for reporting systematic reviews and meta-analyses of studies that evaluate health care interventions: explanation and elaboration. PLoS Med 6:e1000100. https://doi. org/10.1371/journal.pmed.1000100

22. Annabi B, Lachambre MP, Plouffe K, Moumdjian R, Béliveau R (2009) Propranolol adrenergic blockade inhibits human brain endothelial cells tubulogenesis and matrix metalloproteinase-9 secretion. Pharmacol Res 60:438-445. https://doi.org/10.1016/j.phrs. 2009.05.005

23. Balmforth AJ, Ball SG, Freshney RI (1986) D-1 dopaminergic and $\beta$-adrenergic stimulation of adenylate cyclase in a clone derived from the human astrocytoma cell line G-CCM. J Neurochem 47: 715-719

24. Erguven M, Yazihan N, Aktas E, Sabanci A, Chiang JLI, Oktem G, Bilir A (2010) Carvedilol in glioma treatment alone and with imatinib in vitro. Int J Oncol 36:857-866. https://doi.org/10.3892/ijo00000563

25. Homburger V, Gozlan H, Bouhelal R (1985) Irreversible blockade of $\beta$-adrenergic receptors with a bromoacetyl derivative of pindolol. Naunyn Schmiedeberg's Arch Pharmacol 328:279-287. https://doi.org/10.1007/bf00515554

26. Homburger V, Pantaloni C, Lucas M (1984) $\beta$ Adrenergic receptor repopulation of $\mathrm{C} 6$ glioma cells after irreversible blockade and down regulation. J Cell Physiol 121:589-597. https://doi.org/10. 1002/jcp.1041210318

27. Pavlova O, Shirokov A, Fomin A, Navolokin N, Terskov A, Khorovodov A, Namykin A, Pavlov A, Tuchin V, SemyachkinaGlushkovskaya O (2018) Optical in vivo and ex vivo imaging of glioma cells migration via the cerebral vessels: prospective clinical application of the beta2-adrenoreceptors blockade for glioma treatment. J Innov Opt Health Sci 11:1850025. https://doi.org/10.1142/ S1793545818500256

28. Sokolowska $\mathrm{P}$ (2005) Constitutive activity of beta-adrenergic receptors in C6 Glioma cells. Pharmacol Rep 57:659-663

29. Terasaki WL, Linden J, Brooker G (1979) Quantitative relationship between beta-adrenergic receptor number and physiologic responses as studied with a long-lasting beta-adrenergic antagonist. Proc Natl Acad Sci U S A 76:6401-6405

30. Johansen MD, Urup T, Holst CB, Christensen IJ, Grunnet K, Lassen U, Friis S, Poulsen HS (2018) Outcome of bevacizumab therapy in patients with recurrent glioblastoma treated with angiotensin system inhibitors. Cancer Investig 36:512-519. https://doi. org/10.1080/07357907.2018.1544639

31. Asahi M, Wang X, Mori T, Sumii T, Jung JC, Moskowitz MA, Fini ME, Lo EH (2001) Effects of matrix metalloproteinase-9 gene knock-out on the proteolysis of blood-brain barrier and white matter components after cerebral ischemia. J Neurosci 21:7724-7732

32. Shigemori Y, Katayama Y, Mori T, Maeda T, Kawamata T (2006) Matrix metalloproteinase-9 is associated with blood-brain barrier opening and brain edema formation after cortical contusion in rats. Acta Neurochir Suppl 96:130-133

33. Abe T, Mori T, Kohno K, Seiki M, Hayakawa T, Welgus HG, Hori S, Kuwano M (1994) Expression of $72 \mathrm{kDa}$ type IV collagenase and invasion activity of human glioma cells. Clin Exp Metastasis 12:296-304

34. Nakagawa T, Kubota T, Kabuto M, Fujimoto N, Okada Y (1996) Secretion of matrix metalloproteinase-2 ( $72 \mathrm{kD}$ gelatinase/type IV collagenase $=$ gelatinase a) by malignant human glioma cell lines: implications for the growth and cellular invasion of the extracellular matrix. J Neuro-Oncol 28:13-24

35. Audic Y, Hartley RS (2004) Post-transcriptional regulation in cancer. Biol Cell 96:479-498. https://doi.org/10.1016/j.biolcel.2004. 05.002

36. Dalmau J, Furneaux HM, Cordon-Cardo C, Posner JB (1992) The expression of the $\mathrm{Hu}$ (paraneoplastic encephalomyelitis/sensory neuronopathy) antigen in human normal and tumor tissues. Am J Pathol 141:881-886

37. Glisovic T, Bachorik JL, Yong J, Dreyfuss G (2008) RNA-binding proteins and post-transcriptional gene regulation. FEBS Lett 582: 1977-1986. https://doi.org/10.1016/j.febslet.2008.03.004 
38. King PH, Dropcho EJ (1996) Expression of Hel-N1 and Hel-N2 in small-cell lung carcinoma. Ann Neurol 39:679-681. https://doi.org/ 10.1002/ana.410390520

39. Lee SK, Park KK, Kim HJ, Park J, Son SH, Kim KR, Chung WY (2017) Human antigen R-regulated CCL20 contributes to osteolytic breast cancer bone metastasis. Sci Rep 7:9610-9613. https://doi. org/10.1038/s41598-017-09040-4

40. Mitsunari K, Miyata Y, Asai A, Matsuo T, Shida Y, Hakariya T, Sakai H (2016) Human antigen R is positively associated with malignant aggressiveness via upregulation of cell proliferation, migration, and vascular endothelial growth factors and cyclooxygenase-2 in prostate cancer. Transl Res 175:116-128. https://doi.org/10.1016/j.trsl.2016.04.002

41. Sanchez-Diaz P, Penalva LO (2006) Post-transcription meets postgenomic: the saga of RNA binding proteins in a new era. RNA Biol 3:101-109

42. Dai H, Marbach P, Lemaire M, Hayes M, Elmquist WF (2003) Distribution of STI-571 to the brain is limited by P-glycoproteinmediated efflux. J Pharmacol Exp Ther 304:1085-1092. https://doi. org/10.1124/jpet.102.045260

43. Tsuyoshi M, Eiichi T, Keizo K, Hideki S, Katsuya M (1991) Expression of P-glycoprotein in human glioma cell lines and surgical glioma specimens. J Neurosurg 74:460-466. https://doi.org/ 10.3171/jns.1991.74.3.0460

44. Perron L, Bairati I, Harel F, Meyer F (2004) Antihypertensive drug use and the risk of prostate cancer (Canada). Cancer Causes Control 15:535-541. https://doi.org/10.1023/B:CACO.0000036152.58271. $5 \mathrm{e}$

45. Nkontchou G, Aout M, Mahmoudi A, Roulot D, Bourcier V, Grando-Lemaire V, Ganne-Carrie N, Trinchet JC, Vicaut E, Beaugrand M (2012) Effect of long-term propranolol treatment on hepatocellular carcinoma incidence in patients with HCVassociated cirrhosis. Cancer Prev Res (Phila) 5:1007-1014. https://doi.org/10.1158/1940-6207.capr-11-0450
46. Childers WK, Hollenbeak CS, Cheriyath P (2015) Beta-blockers reduce breast cancer recurrence and breast cancer death: a metaanalysis. Clin Breast Cancer 15:426-431. https://doi.org/10.1016/j. clbc.2015.07.001

47. Rao JS (2003) Molecular mechanisms of glioma invasiveness: the role of proteases. Nat Rev Cancer 3:489-501. https://doi.org/10. 1038/nrc1121

48. Beliveau A, Mott JD, Lo A, Chen EI, Koller AA, Yaswen P, Muschler J, Bissell MJ (2010) Raf-induced MMP9 disrupts tissue architecture of human breast cells in three-dimensional culture and is necessary for tumor growth in vivo. Genes Dev 24:2800-2811. https://doi.org/10.1101/gad.1990410

49. Van den Steen PE, Dubois B, Nelissen I, Rudd PM, Dwek RA, Opdenakker G (2002) Biochemistry and molecular biology of gelatinase B or matrix metalloproteinase-9 (MMP-9). Crit Rev Biochem Mol Biol 37:375-536. https://doi.org/10.1080/ 10409230290771546

50. Henriksson R, Asklund T, Poulsen HS (2011) Impact of therapy on quality of life, neurocognitive function and their correlates in glioblastoma multiforme: a review. J Neuro-Oncol 104:639-646. https://doi.org/10.1007/s11060-011-0565-x

51. Bhattacharyya GS, Ranade A, Malhotra H, Babu KG, Shahid T, Parikh PM, Bascomb NF, Chanda AS (2014) Continuous metronomic temozolamide with propranolol and etodolac in recurrent globlastoma: a pilot study. J Clin Oncol 32

52. Shahid T, Bhattacharyya GS, Malhotra H, Govindbabu KS, Parikh PM, Ranade A, Biswas G, Bondarde SA, Chanda A, Bascomb NF (2015) Continuous low dose temozolamide with or without VT-122 in glioblastoma. J Clin Oncol 33

Publisher's note Springer Nature remains neutral with regard to jurisdictional claims in published maps and institutional affiliations. 